\title{
Feed Conversion, Ileal Digestibility and Intestinal Morphology of Broilers Fed Two Feed Forms
}

\author{
"Akande T.O., Olakanmi O. F., Okunlola P.F. and Owolabi E.O. \\ Department of Animal Sciences, Obafemi Awolowo University, Ile-Ife, Osun State, Nigeria \\ *Corresponding Author: Akande T.O, Department of Animal Sciences, Obafemi Awolowo University, Ile- \\ Ife, Osun State, Nigeria
}

\begin{abstract}
This study was conducted to evaluate feed conversion, intestinal morphology and ilea nutrient digestibility of broilers fed pellet and mash feed forms. Two hundred Cobb-500 one-day-old broilers used were randomly grouped into two treatments of five replicates and 20 birds per replicate in a deep litter system. The birds in the first group were fed with $2 \mathrm{~mm}$ and $4 \mathrm{~mm}$ die size pelletized feed at the starter and finisher phase respectively while commercial mash feed grade was applied at the starter and finisher phase for birds in the second group. The experiment lasted 7 weeks. On the last week of the experiment, 4 birds per replicate were separated into the metabolic compartment for the ilea digestibility trial and they were offered feed treated with chromic oxide at $200 \mathrm{mg} / \mathrm{kg}$ diet for five days. On the 6th day, the birds were slaughtered and the ilea contents of the gut were collected for the proximate, energy, and chromic oxide content determination. Performance traits and morphometric measurement of the internal organs and intestinal components of the birds were taken with cut samples preserved in 10\% formalin solution for histological assessment. The result showed a significant difference $(p<0.05)$ in the performance parameters measured with the birds-fed pellet having higher feed intake, body weight gained, and better feed conversion ratio. There was no significant difference $(p>0.05)$ in the length of the duodenum, jejunum, and ileum, including organ weights (heart and liver) between the two treatments while the gizzard weight was higher $(P<0.05)$ in birds fed mash feed form. Ilea nutrient digestibility for ether extract was higher ( $p<0.05)$ in birds on pellet. It was deduced from the results that although mash feed form improved gizzard development, better feed conversion was observed in birds fed pellet feed form with significant positive influence on the gut morphometric and ilea nutrient digestibility.
\end{abstract}

Keywords: broiler, feed conversion, feed form, gut morphology, ilea digestibility,

\section{INTRODUCTION}

The nutritional requirement for poultry production is well-established, however, the evaluation of the feed form for chickens still needs further scrutiny as there were ample studies with differing results. Feed composition, feed structure, and feed forms remain the most important factors that determine the efficiency of feed utilization by animals particularly poultry because of the simple nature of their stomach $[1,2]$. Modern meat-type chicken has a high appetite for feed which translates to increased production costs in which feed alone claims about $60-70 \%$ of the total cost [3]. Therefore, broilers' feed consumption pattern and utilization should be well studied to ensure optimum performance of the birds at the minimum possible cost.

The growth and development of the gastrointestinal tract are vital for broiler chickens as it helps to effectively utilize nutrients in their diet [4] Feeds fed to broiler can assume different forms such as pellets, mash, and crumble due to differences in processing methods during feed formulation. Mash is a form of a complete feed that is finely ground and mixed so that birds cannot easily separate ingredients; crumble also is a type of feed prepared at the mill by pelleting of the mixed ingredients and then crushing the pellet to a consistency coarser than mash; while pellet is a small feed form (using different dies depending on the desired size) rounded and compressed into a mass of a substance. Reports indicate that the pelleting process was introduced to convert fibrous, bulky, finely-ground, and unpalatable blends of feed ingredients into a compact, free-flowing form that facilitates easy prehension $[5,6]$.

ARC Journal of Animal and Veterinary Sciences 
Recent studies on the management, nutrition, genetics, and other husbandry practices have led to the shift from fibrous and poorly digestible feedstuffs to the use of low fiber, texture-less, and diets enriched in nutrients. These changes have affected the development, functionality, and health of the gastrointestinal tract, which in turn affects nutrient digestibility and also limits the advantages generated by processing methods such as steam-pelleting [7,8]. Ilea digestibility which collects digesta from part of the ileum is a more complex method of measuring digestibility but tactically eliminates some confounding factors such as urine and microbial contributions into the excreta which may produce overestimation of nutrient utilization. This study was therefore set to determine the comparative effect of two feed forms (mash and pellet) on the feed conversion of broiler chicken, gut characteristics, and the ilea nutrient digestibility of the birds.

\section{Materials ANd Methodology}

\section{Experimental Station and Birds Management}

The experiment was approved by the Committee for Animal Research in the Department of Animal Sciences, Obafemi Awolowo University (OAU) Ile-Ife and conducted at the Poultry Unit of Teaching and Research Farm, OAU, Nigeria within August and October in 2019. Two hundred (COBB-500) straight run day old as hatched broilers chicks were obtained, brooded, and fed a commercial starter feed $23 \%$ crude protein and $3100 \mathrm{kcal} / \mathrm{kg}$ metabolizable energy) together for the first one week. A charcoal heating system was used to keep the required temperature (started with $34^{\circ} \mathrm{C}$ and decreased to $30^{\circ} \mathrm{C}$ at end of the week). The light was provided $22 \mathrm{~h}$ a day throughout the week. At the end of the first week, they were divided into two treatment groups of 5 replicates with 20 chicks each. The birds were reared in floor pens $1 \times 2$ square meters cell for each replicate.

\section{Experimental Diets}

The ingredients used for the feed formulation were purchased from a reputable commercial feed mill in Ile-Ife, Nigeria while the milling, mixing and pelleting were carried out at OAU Teaching and Research Farm. The gross compositions of the experimental diets are as shown in Table 1.

\section{Data Collection and Analysis}

The experiment lasted 42 days for the feeding trial and day 43-47 for the digestibility trial. At the end of every week, birds in each replicate were weighed and their feed intake measured by subtracting the leftover from the total weight of feed allotted to each replicate at the start of the week. Bodyweight gain was measured each week while feed conversion was calculated as ration of total feed intake and total body weight gained. At day 43, four representative birds with bodyweight close to the group average were selected from each replicate for digestibility trial and gut measurement. For the digestibility trial, birds were fed 200mg chromic oxide $\left(\mathrm{Cr}_{2} \mathrm{O}_{3}\right)$ per $\mathrm{kg}$ diet as non-digestible marker. A feeding period of 5 days was applied to ensure stabilized excretion in the ileum. The birds were stimulated (by feed restriction and then fed 4 hours to ilea collection) to consume the feed to maximize ilea content collection.

Following the sacrifice by cervical dislocation, abdominal incisions were made to expose the small intestine and the duodenum, jejunum and ileum were separated. The length of these three compartments were taken separately using a measuring tape while small portion of the duodenum and jejunum were cut and preserved in $10 \%$ formalin for histological assessment. All the samples were collected within one hour after sacrifice. The samples were processed following standard histological methods. The prepared samples were screened under a light microscope at $(x 40)$ the objective magnification. Villus height and crypt depth were measured using the NIS-Elements version 3.0 software. The height of each villus was measured from the apex of the villus to the crypt transition, and the crypt depth was defined as the invagination between two villi [9]. Values were based on the average of all measurements taken.

The sampling of the ilea content of the intestine was standardized by taking sample $30 \mathrm{~mm}$ before the ileocecal junction and $30 \mathrm{~mm}$ after Meckel's diverticulum, to avoid contamination of the ceca and jejuna flow respectively, and adjust to individual variability in the intestinal tract length of birds. Contents from the ileum were collected by gentle finger-stripping directly into in a labeled specimen jar per replicate. Samples were held on the ice during collection and taken to laboratory homogenized and oven-dried $\left(60^{\circ} \mathrm{C}\right)$ 
for $48 \mathrm{hr}$, ground $(0.5 \mathrm{~mm}$ screen), and stored at $4^{\circ} \mathrm{C}$ in airtight labeled bags for further analysis. Samples were later analyzed for levels of dry matter, crude protein, ether extract according to the methodology of [10]; gross energy was determined by a bomb calorimeter while the quantitative determination of chromic oxide content in the samples involved the oxidation of water-insoluble trivalent chromic oxide to its water-soluble hexavalent form [11]. Marker recovery in excreta was calculated as the total amount of $\mathrm{Cr}$ excreted relative to the total amount of $\mathrm{Cr}$ consumed. The apparent ilea digestibility coefficients of dry matter, crude protein, ether extract, and gross energy of different diets fed were isolated using the following calculations:

$\operatorname{ADE}(\mathrm{kcal} / \mathrm{kg}$ of diet $)=$ GEdiet $-\left[\mathrm{GE}_{\text {digesta }} \times\left(\right.\right.$ Marker $_{\text {diet }} /$ Marker $\left.\left._{\text {digesta }}\right)\right][12]$

Apparent nutrient digestibility $=\frac{\frac{\text { Nutrient in feed }}{\text { marker in feed }}-\frac{\text { Nutrient in ileum }}{\text { marker in ileum }}}{\frac{\text { Nutrient in feed }}{\text { marker in feed }}}$

Data generated were analyzed using student T-test using SAS statistical package [14].

\section{RESUlts AND DiscusSion}

\section{Feed Conversion of Broiler Fed Mash and Pellet Feed Forms}

Data on performance traits are presented in Table

2. The result shows that all performance parameters were significantly different $(\mathrm{p}<0.05)$ between the treatments. The higher total feed intake (TFI) in birds fed pellets may be as a result of the fact that the ingredients in pellets have been bound together in units and at every point, the birds are pick the pellets, they pick almost the whole ingredient at once which is not the case with birds fed mash feed form. Also, lesser energy and time are required in prehension by birds fed pellets, unlike in the birds fed mash where relatively more time was spent in picking various ingredients in the feed before satisfaction. In other words, the number of pecks to eat mash feed form is higher compared to pellets. General observation (data not taken) also revealed possible high feed wastage in mash feed form as feed particles were much noticeable in litter of birds on mash feed form. The higher final body weight (FBW) and gain in birds fed pellet have a positive correlation with the feed intake. The improved feed conversion ratio (FCR) in pellets affirms the fact that the birds-fed pellet utilized the feed better than birds fed mash. Jahan et al. and Dozier et al. $[15,16]$ also reported a significant difference in the FCR, FBW, TFI between broiler fed pellet and those fed mash where birds fed pellet assumed a higher value for FBW, TFI, BWG, and a lower value for FCR, which is in total agreement with the result of this experiment. Ferket and Gernat [17] reported that when viscous grains such as wheat are finely ground and not pelleted feed intake is compromised and consumption becomes very difficult due to the formation of a viscous sticky saliva-food mass in bird's mouth and beak pasting caused by wheat gluten, this may the case for the lower feed intake observed with birds on the mashed diet. The finding aligned with other reports on numerous advantages associated with pelleting which include enhancement of feed intake and growth of animals as a result of the reduction in feed wastage, decreasing of energy used for consumption, improving palatability, and the reduction of the dustiness of feed [18, 19]. However, a marginal increase in cost is expected with a bird on pellet because of extra cost accrued from pelleting [15].

\section{Organ, Gut Morphology and Ilea Digestibility of Broiler Fed Mash and Pellet Feed Forms}

The result of the organ measurement, intestinal morphometric, and histology of the duodenum and jejunum are as indicated in Table 3. Among 
organs measured, gizzard was significantly bigger $(\mathrm{P}<0.05)$ in birds fed mash feed. It should be noted that feed particle size are reduced during pelleting to ensure proper binding into pellets, this causes small particles to be retained in the gizzard for lesser time than birds on mash feed with more coarse particles particular during the finishing stage. This influences less mechanical stimulation in gizzard of birds fed pellet and possibly responsible gizzard size variations in the two groups as shown in the Table 3. Available literature favors the use of mash diets for proper gizzard growth than pelleted diets. The large and well-developed gizzard can grind feed particles more finely and influence the secretion of pancreatic enzymes through the higher release of cholecystokinin which will enhance higher proteolysis and gastrointestinal tract motility for improved nutrient digestibility [7,20]. This means that mash feed is expected to favor higher nutrient digestibility contrary to what was obtained in this study.

Enzymatic feed digestion and absorption take place majorly in the duodenum, the jejunum and partially in the ileum aided by the presence of the villus and crypt. Any changes observed in the villus and crypt have been indicated to influence the rate of digestion and absorption as these components determine the surface area of the inner intestine that expose the feed to enzymatic reaction. The result in Table 3 shows that the duodenum of birds is marginally longer $(\mathrm{P}>0.05)$ in mash feed form while ileum is marginally longer $(\mathrm{P}>0.05)$ in birds fed pellet diet. This intestinal measurement did not correlate with the body size as one expects birds on the pelleted diet with higher $(\mathrm{P}<0.05)$ body weight to have a longer intestine. Although these values were not significantly different $(\mathrm{P}>0.05)$, it also suggests that the feed form could influence the morphology of the intestine. Considering the particle size in the two feed forms, mash feed had a higher particle size particularly at the finishing stage which invariably increased the activities in the intestine responsible for the stretching of the intestine. Several studies have also reported lower relative length of the different segments of the digestive tract of birds fed pelleted diets compared to those fed mash diets $[18,20,21]$.

However, histological observation (Plate 1) and Table 3 showed that villus height of the duodenum and jejunum of birds fed pellet was significantly longer $(\mathrm{P}<0.5)$ than birds on mash feed. The villi serve as the direct surface for absorption. The higher feed intake observed in birds fed pellet is expected to increase the activity of the villus in the intestine. The increased villus height may also increase the total luminal villus absorptive area and subsequently result in greater digestive enzyme action and enhanced transport and absorption of nutrients at the villus surface [22]. These higher values of the villus height of duodenum and jejunum and higher value of the crypt depth of jejunum observed in birds fed pellets may be responsible for the better feed conversion indicated. The results corroborate the findings of $[20,23]$ who reported an increase in the villus height and crypt depth of birds fed pelleted diets compared with mash diet.

Although, there was a marginal rise in dry matter digestibility in the experimental birds, both crude protein and ether extract digestibility were significantly higher $(\mathrm{P}<0.05)$ with pellet (Table 4). It was a general opinion that the larger surface area of the feed ingredient would possibly allow for greater interaction with digestive enzymes in the intestine and result in higher nutrient digestibility. This assertion may explain reasons for higher protein and fat digestibility with pellet feed. These results deviate partly from some reports in the literature that affirmed that feeding pelleted diets did not affect nitrogen and starch or fat, $\mathrm{Ca}$ and $\mathrm{P}$ ileal digestibility in maize-based diets $[18,24]$. Large particle size aided by some structural components is however considered 
beneficial to gizzard functions and gut development.

\section{CONCLUSION}

It was concluded that the two feed forms, mash, and pellet have varied impacts on feed conversion, the morphology of intestines, and ileal nutrient digestibility. Mash feed form improved gizzard development which favors better grinding of feed particles, but not

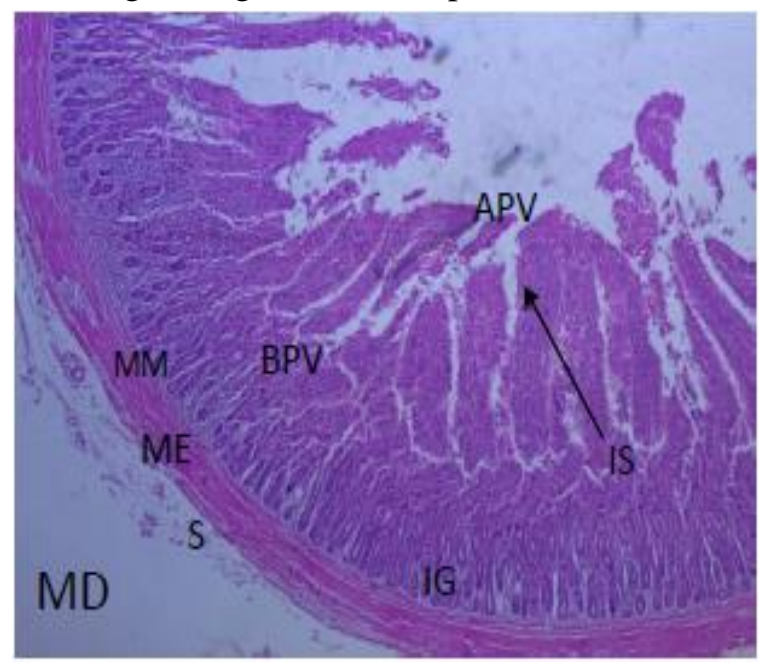

A representative sample of the duodenum of birds on mash feed MD

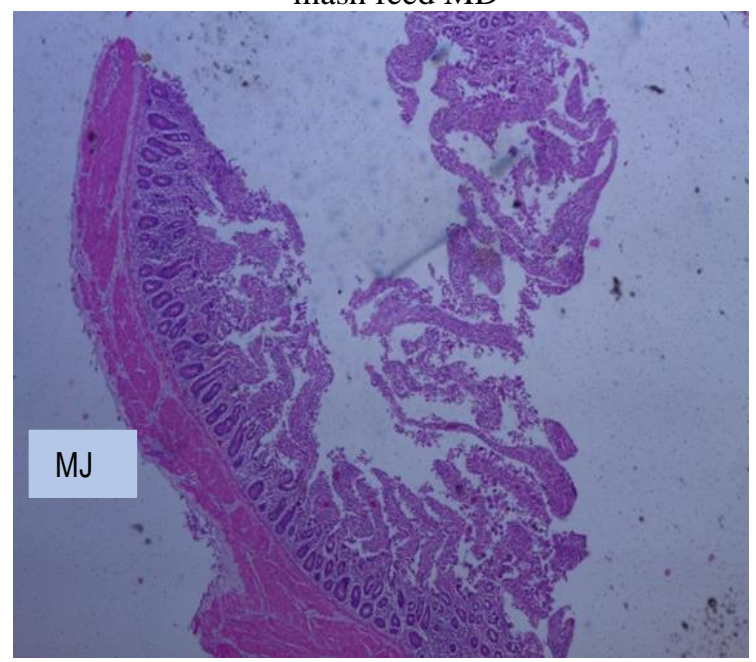

A representative sample of the jejunum of birds on mash feed MJ

Plate1: Representative photomicrograph of broiler's duodenum, D, and jejunum J on Pellet (P) and Marsh (M) feed forms. Observation revealed normal duodenum architecture characterized by flat mucosa surface of the simple columnar epithelium (SE) with apical parts of villi (APV) slightly pointed and clear translated to better nutrient utilization in experimental birds. Pellet feed improves both the villus height and crypt depth which favor total luminal absorptive area for enhanced absorption of nutrients. While pellet diet is recommended based on superior feed conversion and better nutrient digestibility, the choice of feed form may be dependent on the composition of the actual feed and type of poultry.

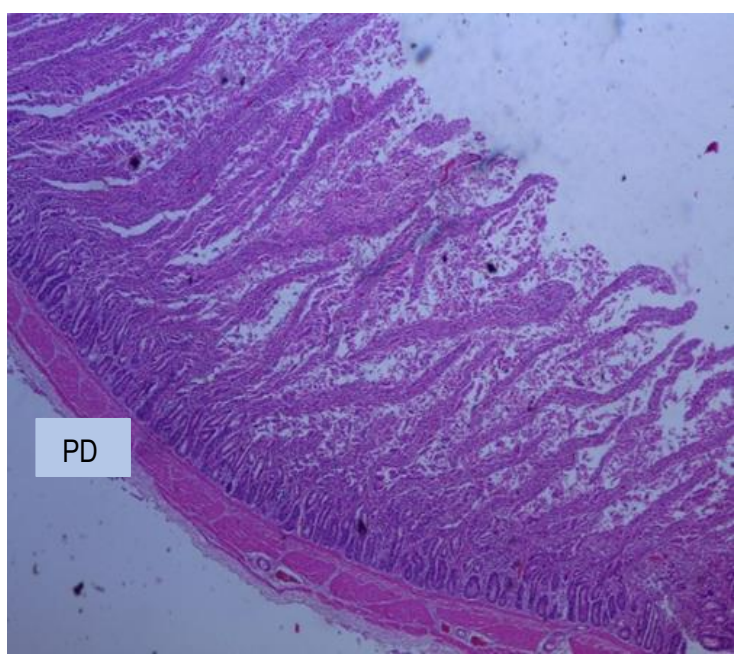

A representative sample of the duodenum of birds on pellet feed PD

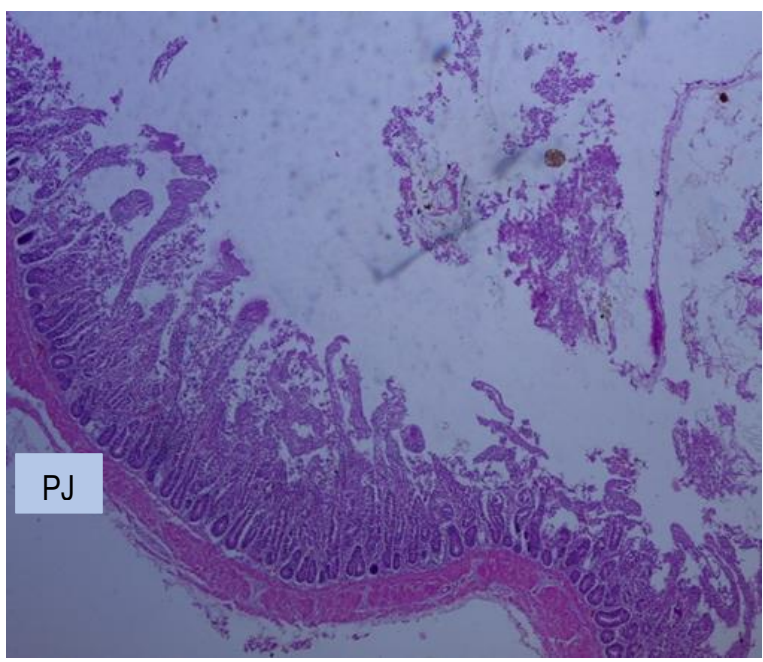

A representative sample of the jejunum of birds on pellet feed PJ

basal parts of villi wider (BPV), Muscularis Mucosa (MM), Muscularis External (ME) and Serosa (S), Intestinal gland (IG) and Intervilli space (IS). The integrity of intestinal epithelium both in the pellet and mash are intact. H and E @ $\mathrm{x} 40$ 
Feed Conversion, Ileal Digestibility and Intestinal Morphology of Broilers Fed Two Feed Forms

Table1. Gross composition of the experimental diets

\begin{tabular}{|l|l|l|}
\hline Ingredients & Starter & Finisher \\
\hline Maize & 56.00 & 58.00 \\
\hline Soybean meal & 20.00 & 10.00 \\
\hline Groundnut Cake & 11.00 & 17.50 \\
\hline Palm kernel Cake & 4.55 & 8.00 \\
\hline${ }^{+}$Other ingredient & $* * 8.45$ & $* 6.50$ \\
\hline TOTAL & $\mathbf{1 0 0}$ & $\mathbf{1 0 0}$ \\
\hline Calculated analysis & & \\
\hline ME(Kcal/Kg) & 3027 & 2985 \\
\hline Crude Protein (\%) & 23.01 & 20.27 \\
\hline Ether extract (\%) & 5.30 & 5.45 \\
\hline Crude fibre (\%) & 3.50 & 3.75 \\
\hline Determined Analysis,(\%) & Mash (Finisher) & Pellet (finisher) \\
\hline Dry matter & 91.50 & 90.85 \\
\hline Crude Protein & $21.33 \pm 0.50$ & $21.68 \pm 0.43$ \\
\hline Ether extract & $4.53 \pm 0.24$ & $4.44 \pm 0.35$ \\
\hline Crude fibre & $5.80 \pm 0.41$ & $5.47 \pm 0.61$ \\
\hline Ash & $7.18 \pm 0.93$ & $8.20 \pm 0.74$ \\
\hline NFE & $52.66 \pm 2.13$ & $51.06 \pm 1.35$ \\
\hline GE(Kcal/Kg) & 4502.34 & 4321.55 \\
\hline & & \\
\hline
\end{tabular}

+Others:

$* 6.5$ : Fish meal =2.0; Bone meal =2.5; Oyster shell $=1.0 ; \quad{ }^{++}$Premix $=0.3 ; \quad$ Lysine $=0.3$, Methionine $=0.2 ; \quad$ Salt $=0.2$

$* * 8.45$ : Fish meal $=4.0$; Bone meal $=2.5$; Oyster shell $=1.0 ; \quad$ Premix $=0.3 ; \quad$ Lysine $=0.3$, Methionine $=0.2 ;$ Salt $=0.2$
${ }^{++}$Vitamin and mineral premix contain the following per kg diet. Vitamins A 10,000 IU, D3 $3000 \mathrm{IU}, \mathrm{E} 8.0 \mathrm{IU}, \mathrm{K} 2.0 \mathrm{mg}$, B6 $1.2 \mathrm{mg}$ and B12 $0.12 \mu \mathrm{g}$; niacin $1.0 \mathrm{mg}$; pantothenic acid $7.0 \mathrm{mg}$; folic acid $0.6 \mathrm{mg}$; choline chloride $500 \mathrm{mg}$; Minerals: Fe $60 \mathrm{mg}, \mathrm{Mn} 80 \mathrm{mg}, \mathrm{Mg} 100 \mathrm{mg}, \mathrm{Cu}$ $8.0 \mathrm{mg}$, Zn $50 \mathrm{mg}$, Co $0.45 \mu \mathrm{g}$, I $2.0 \mathrm{mg}$, Se 0.1 $\mathrm{mg}$.

Table2. Performance characteristics of broiler chicken fed two feed forms

\begin{tabular}{|l|l|l|l|}
\hline Treatment & Mash & Pellet & P value \\
\hline Initial body weight $(\mathrm{g})$ & $152.52 \pm 0.8869$ & $152.16 \pm 1.0348$ & 0.80 \\
\hline Final body weight $(\mathrm{g})$ & $2473.7 \pm 29667^{\mathrm{a}}$ & $2992.3 \pm 91.167^{\mathrm{b}}$ & 0.01 \\
\hline Body weight gain $(\mathrm{g})$ & $2321.1 \pm 29.873^{\mathrm{a}}$ & $2840.2 \pm 91.31^{\mathrm{b}}$ & 0.03 \\
\hline Daily weight gain $(\mathrm{g})$ & $55.265 \pm 0.7113^{\mathrm{a}}$ & $67.263 \pm 2.1743^{\mathrm{b}}$ & 0.04 \\
\hline Total feed intake (g) & $4964 \pm 70.62^{\mathrm{a}}$ & $5533 \pm 102.8^{\mathrm{b}}$ & 0.01 \\
\hline Feed conversion ratio & $2.14 \pm 0.029^{\mathrm{a}}$ & $1.95 \pm 0.06^{\mathrm{b}}$ & 0.04 \\
\hline Mortality & 0 & 0 & \\
\hline
\end{tabular}

**ab means in the same column followed by different letter are significantly different. $\mathrm{P}<0.05$ 
Table3. Organ and intestinal measurement of broiler chickens fed two feed forms

\begin{tabular}{|l|l|l|l|}
\hline Treatment & Mash & Pellet & P-value \\
\hline Duodenum $(\mathrm{cm})$ & $46.00 \pm 3.03$ & $45.00 \pm 6.02$ & 0.70 \\
\hline Jejunum $(\mathrm{cm})$ & $85.50 \pm 6.36$ & $80.50 \pm 3.50$ & 0.11 \\
\hline Ileum $(\mathrm{cm})$ & $88.00 \pm 10$ & $93.00 \pm 2.887$ & 0.43 \\
\hline & & & \\
\hline Gizzard $(\mathrm{g})$ & $57.00 \pm 2.00^{\mathrm{a}}$ & $38.50 \pm 0.50^{\mathrm{b}}$ & 0.02 \\
\hline Liver $(\mathrm{g})$ & $23.00 \pm 2.00$ & $23.500 \pm 4.50$ & 0.83 \\
\hline Heart $(\mathrm{g})$ & $12.00 \pm 2.00$ & $14.00 \pm 1.00$ & 0.17 \\
\hline & & & \\
\hline Duodenum villus height $(\mu \mathrm{m})$ & $1829.30 \pm 78.76^{\mathrm{b}}$ & $2349.9 \pm 65.54^{\mathrm{a}}$ & 0.01 \\
\hline Duodenum depth of crypt $(\mu \mathrm{m})$ & $520.95 \pm 14.74$ & $504.95 \pm 16.69$ & 0.47 \\
\hline Duodenum villus height-depth of crypt ratio & $3.51 \pm 0.32^{\mathrm{b}}$ & $4.66 \pm 0.45^{\mathrm{a}}$ & 0.03 \\
\hline Jejunum villus height $(\mu \mathrm{m})$ & $964.56 \pm 46.71^{\mathrm{b}}$ & $1443.50 \pm 27.84^{\mathrm{a}}$ & 0.02 \\
\hline Jejunum depth of crypt $\mu \mathrm{m})$ & $356.05 \pm 20.51^{\mathrm{b}}$ & $441.77 \pm 18.33^{\mathrm{a}}$ & 0.04 \\
\hline Jejunum villus height-depth of crypt ratio & $2.71 \pm 0.31$ & $3.27 \pm 0.33$ & 0.73 \\
\hline
\end{tabular}

**ab means in the same column followed by different letters are significantly different. $\mathrm{P}<0.05$

Table4. Ileal digestibility of broiler chicken fed two feed forms

\begin{tabular}{|l|l|l|l|}
\hline Item & Mash & Pellet & P-value \\
\hline Chromium, g & 0.72 & 0.81 & 0.70 \\
\hline Dry Matter, \% & $66.56 \pm 1.52$ & $69.70 \pm 1.23$ & 0.71 \\
\hline Crude protein, \% & $75.99^{\mathrm{b}} \pm 1.25$ & $80.98^{\mathrm{a}} \pm 1.55$ & 0.04 \\
\hline Ether extract, \% & $84.07^{\mathrm{b}} \pm 2.05$ & $88.04^{\mathrm{a}} 3 \pm .20$ & 0.05 \\
\hline ADE, \% & $75.04 \pm 2.23$ & $79.77 \pm 2.49$ & 0.06 \\
\hline
\end{tabular}

\section{REFERENCES}

[1]. Choct M., Selby E.A.D., Cadogan D. J., Campbell R.G. Effect of particle size, processing, and dry or liquid feeding on performance of piglets. Australian Journal of Agricultural Research 2004,55: 237-245.

[2]. Ball M.E.E., Magowan E., McCracken K.J., Beattie V.E., Bradford R. et al. An investigation into the effect of dietary particle size and pelleting of diets for finishing pigs. Livestock Science 2015, 173: 48-54

[3]. Aliakbarpour H.R., Chamani M., Rahimi G., Sadeghi A.A., Qujeq D. Intermittent feeding program and addition of Bacillus subtilis based probiotics to the diet of growing broiler chickens: influence on growth, hepatic enzymes, and serum lipid metabolites profile. Archive of Animal Breeding 2013, 56: 410-422.

[4]. Jacobs C.M., Utterback P.L., Parsons C.M. Effect of corn particle size on growth performance and nutrient utilisation in young chicks. Poultry Science 2010, 89: 539-544

[5]. Brickett K.E., Dahiya J.P., Classen H.L., Gomis S. Influence of dietary nutrient density, feed form and lighting on growth and meat yield of broiler chickens. Poultry Science 2007,86: 2172-2181

[6]. Coffey D., Dawson K.A., Ferket P., Connolly A. Review of the feed industry from a historical perspective and implications for its future. Journal of Applied Animal Nutrition 4: 1-11.
[7]. Svihus B. 2011. The gizzard: Function, influence of diet structure and effect on nutrient availability. World's Poultry Science Journal 2016, 67: 207-224. 12.

[8]. Mateos G.G., Jimenez-Moreno E., Serrano M.P., Lazaro R. Poultry response to high levels of dietary fibre sources varying in physical and chemical characteristics. Journal of Applied Poultry Research 2012, 21: 156-174.

[9]. Brudnicki A., Brudnicki W., Szymeczko R., Bednarczyk M., Pietruszynska D., KirkilloStacewicz K. Histo-morphometric adaptation in the small intestine of broiler chicken, after embryonic exposure to a-Galactosides. Journal of Animal and Plant Science 2017, 27: 1075-1082.

[10]. AOAC. Official Methods of Analysis of the Association Analytical Chemistry Revised Edition. 13 ${ }^{\text {th }}$ Edition Washington D.C. The United States of America. 2009.Pg 1094.

[11]. Divakaran S., Obaldo L. and Forster I.P. Note on the methods for determination of chromic oxide in shrimp feeds. Journal of Agricultural and Food Chemistry, 2002, 50, 464-467.

[12]. Scott T.A., Boldaji F. Comparison of inert markers [chromic oxide or insoluble ash (Celite)] for determining apparent metabolizable energy of wheat- or barley-based broiler diets with or without enzymes. Poultry Science, 1997,76(4):594-598. 
[13]. Khieu, B, Brian O and Jan EL. Methods and Techniques for the Determination of Amino Acid Digestibility. Livestock Research for Rural Development, 2002:14.

[14]. SAS. SAS User's guide, version 9.1 for windows, Statistical Analysis Systems Institute, Inc., Cary, NC, U. S. A. 2009.

[15]. Jahan M.S., Asaduzzaman M .and Sarkar A.K. Performance of Broiler Fed on Mash, Pellet and Crumble. International Journal of Poultry Science 2006, 5 (3): 265-270.

[16]. Dozier W.A., Behnke K.C., Gehring C.K., Branton S.L. Effects of feed form on growth performance and processing yields of broiler chickens during a 42-day production period. Journal of Applied Poultry Research 2010, 19:219-226

[17]. Ferket P.R., Gernat A.G. Factors that affect feed intake of meat birds: a review. International Journal of Poultry Science 2006,5: 905-911.

[18]. Abdollahi M.R., Ravindran V., Svihus B. Influence of grain type and feed form on performance, apparent metabolizable energy, and ileal digestibility of nitrogen, starch, fat, calcium, and phosphorus in broiler starters. Animal Feed Science and Technology 2013, 186: 193-203.

[19]. Wan, Y.; Ma, R.; Khalid, A.; Chai, L.; Qi, R.; Liu, W.; Li, J.; Li, Y.; Zhan, K. Effect of the

[20]. Pellet and Mash Feed Forms on the Productive Performance, Egg Quality, Nutrient Metabolism, and Intestinal Morphology of Two Laying Hen Breeds. Animals 2021, 11:701.
[21]. Amerah A.M., Ravindran V., Lentle R.G., Thomas D.G. Influence of feed particle size and feed form on the performance, energy utilization, digestive tract development, and digesta parameters of broiler starters. Poultry Science 2007, 86: 2615-2623.

[22]. Engberg R.M., Hedemann M.S., Jensen B.B. The influence of grinding and pelleting of feed on the microbial composition and activity in the digestive tract of broiler chickens. British Poultry Science 2002, 43: 569-579.

[23]. Naderinejad S., Zaefarian F., Abdollahi M.R., Hassanabadi A., Kermanshahi H., Ravindran V. Influence of feed form and particle size on performance nutrient utilization, and gastrointestinal tract development and morphometry in broiler starters fed maizebased diets. Animal Feed Science and Technology 2016, 215: 92-104.

[24]. Zang JJ, Piao XS, Huang DS, Wang JJ, Ma X. et al. Effects of feed particle size and feed form on growth performance: nutrient metabolisability and intestinal morphology in broiler chickens. Asian-Australian Journal of Animal Science 2009, 22: 107-112.

[25]. Aguzey AH, Gao Z, Haohao W, Guilan C. Influence of Feed Form and Particle Size on Gizzard, Intestinal Morphology and Microbiota Composition of Broiler Chicken. Poultry Fish and Wildlife Science 2018, 6:2. DOI: 10.4172/2375-446X.1000196

Citation: Akande T.O*., Olakanmi O. F., Okunlola P.F. and Owolabi E.O. Feed Conversion, Ileal Digestibility and Intestinal Morphology of Broilers Fed Two Feed Forms. ARC Journal of Animal and Veterinary Sciences. 2021; 7(1): 7-14. DOI: https://doi.org/10.20431/2455-2518.0701002.

Copyright: (C) 2021 Authors. This is an open-access article distributed under the terms of the Creative Commons Attribution License, which permits unrestricted use, distribution, and reproduction in any medium, 